
Research Square
Preprints are preliminary reports that have not undergone peer review.
They should not be considered conclusive, used to inform clinical practice, or referenced by the media as validated information.

\title{
The impact of previous cesarean section on the outcome in patients with non-adherent placenta previa
}

\author{
Amer Sindiani ( $\sim$ amsindiani0@just.edu.jo ) \\ Jordan University of Science and Technology
}

\section{Research Article}

Keywords: Cesarean section, Non-adherent placenta, Placenta previa, Previous cesarean

Posted Date: December 11th, 2020

DOl: https://doi.org/10.21203/rs.3.rs-125152/v1

License: (c) (i) This work is licensed under a Creative Commons Attribution 4.0 International License.

Read Full License 


\section{Abstract}

Background: to evaluate the impact of lower segment cesarean section (LSCS) on the maternal and fetal outcomes of women with non-adherent placenta previa (PP).

Methods: This is a retrospective study of all women who delivered at our hospital by LSCS with nonadherent PP over a period of 10 years. Data were obtained through hospital registry and medical records search. Data were analyzed using the Statistical Package for Social Sciences (SPSS, version 20). The differences in demographic and obstetric characteristics, peripartum complications, and fetal outcomes between women with no previous CS and those with previous CS were analyzed using $t$ test or chi-square test wherever appropriate. A p-value of less than 0.05 was considered statistically significant.

Results A total of 90 women with non-adherent placenta were included, 54 women with no previous CS and 36 women with previous CS. Women with previous CS were significantly more likely to experience organ injury ( $p$-value $<0.005$ ), transfusion of $\geq 4$ units of PRBC ( $p$-value $=0.034)$, transfusion of FFP ( $p$ value $=0.034)$, and hysterectomy or other procedure ( $B$ Lynch, Uterine artery ligation) use ( $p$-value $<0.005)$

Conclusion: There is a significant increase in the incidence of maternal morbidities such as hysterectomy, blood transfusion and organ injury in patients with non-adherent PP with previous CS, with no difference in perinatal outcome in the same group of patients.

\section{Background}

Although the etiology of placenta previa (PP) remains unclear, many studies showed that the incidence of PP has been rising in parallel with the increasing rate of cesarean delivery.(1-6) The rate of primary and overall cesarean section (CS) has been steadily and significantly rising for the last decades in all developed countries with worldwide variation; In the USA, the rate increased from $21.5 \%$ in 1996 to $32.9 \%$ in 2006 .(7) This increase has been attributed to multiple factors, including increased maternal request and obstetrician's preferences for CS. $(8,9)$ In addition to its associated risk of short term maternal morbidities like wound infections, postpartum hemorrhage, and endomyometritis, (10-12) CS is associated with PP in future pregnancies.

PP is a major obstetric emergency associated with increase in the risk of maternal and perinatal morbidity and mortality, because of massive hemorrhage, risk from emergency delivery, hysterectomy and the serious risk from massive blood transfusion $(13,14)$.Furthermore, there is increased risk of morbidly adherent placenta previa (MAPP) accreta, increta and percreta, a life-threatening condition often associated with significant maternal morbidity and mortality. While the serious maternal risk related to the morbidly adherent placenta previa is well established (14-16), few studies have explored the outcome of non-adherent placenta previa in women with previous one or more lower transverse cesarean section (LTCS). 
This study was conducted to determine the impact of previous cesarean section on the maternal and fetal outcomes among women with non-adherent PP.

\section{Material And Methods}

A retrospective study was conducted over 10 years from (January 2007-December 2017) to evaluate the impact of previous cesarean section on the outcome in patients with non-adherent PP in a tertiary care hospital in the North of Jordan: King Abdullah University Hospital (KAUH). This study was approved by the institutional review board in the Jordan University of Science and Technology, no consent form was required. KAUH is a tertiary referral hospital serving wide geographical area in the North of Jordan with a current delivery rate of 3000 per year. Ultrasonography for diagnosis of PP is basically performed by properly trained obstetric consultants. Doppler studies are used in suspected MAPP. The hospital has 24 hours blood transfusion services available with surgical and medical teams available on request. Delivery is usually performed by specialists or trained senior residents staff member. Hospital registry was searched for all women delivered during the study period because of PP by CS or cesarean hysterectomy (both elective and emergency). The demographic and obstetric characteristics were collected from their medical records, also the antenatal course of the pregnancy. Patients with MAPP were excluded from the study. Operative notes were reviewed to confirm placental site clearly. Any intraoperative complications like organ injury, blood transfusion, hysterectomy or other interventions such as uterine artery ligation BLynch were recorded. Transfer to ICU and post-operative hospital stay were also recorded. The perinatal outcome included all the following: GA at delivery, Apgar scores, NICU admissions, birth weight and the need for Surfactant.

Data were analyzed using the Statistical Package for Social Sciences (SPSS, version 20). The differences in demographic and obstetric characteristics, peripartum complications, and fetal outcomes between women with no previous CS and those with previous CS were analyzed using t test or chi-square test wherever appropriate. A p-value of less than 0.05 was considered statistically significant.

\section{Results}

This study included a total of 119 women with PP. Of those women, 29 were excluded because they had morbidly adherent PP. Ninety women with non-adherent placenta were included, 54 women with no previous CS and 36 women with previous CS (15 were with previous one CS, 12 with previous two CS and 9 with previous $\geq$ three CS). The highest number of previous CS in the study group was 6 . Women with previous CS were significantly older, had higher number of deliveries, and were more likely to have previous miscarriages and evacuations compared to women with no previous CS (Table 1). Anterior and central placental locations were more common in women with previous CS. The two groups of women did not differ significantly in other characteristics including bleeding during pregnancy, the indications for delivery, and gestational age at delivery. 
Table 2 shows the peripartum complications among women with no previous CS and those with previous CS. Women with previous CS were significantly more likely to experience organ injury, transfusion of $\geq 4$ units of packed red blood cells (PRBC), transfusion of fresh frozen plasma (FFP), and hysterectomy. Both groups had similar rates of ICU admissions and postoperative hospital stay.

Table 3 shows the differences in perinatal outcomes between the two groups. Both groups of women did not differ significantly in gestational age at delivery. The means of Apgar score and birth weight were similar in both groups. The rate of admission to NICU was almost similar in both groups.

\section{Discussion}

PP complicated $0.4 \%$ of all deliveries, with significant increasing trend in its incidence in the past two decades, which is mainly due to an increasing rate of cesarean sections (CSR) worldwide. $(2,13,16)$ International concerns over such increases have prompted the World Health Organization to suggest that CSR should not exceed 15\%; (17)additionally, there are well-documented adverse health outcomes associated with cesarean birth, both for the woman and her infant. $(11,12,18)$ In addition, the rate of MAPP has increased as a result of more previous caesarean sections with its major maternal and perinatal complications which are well documented by many studies. $(14,15,19,20)$ Those studies concentrated on the relationship between previous CS and MAPP but unfortunately to our knowledge, no studies focused only on the impact of cesarean section on PP that is not adherent.

Our study demonstrated that maternal morbidity was higher in the group of women with prior LTCS, they were more likely to experience intraoperative organ injury, transfusion of $\geq 4$ units of PRBC, transfusion of FFP, and hysterectomy. These findings are comparable to the results of some studies which were conducted only on women with previous CS but without PP. Studies demonstrated that complications were progressively increased by each additional CS, which is not reported in our study. $(14,16,21)$

Ayaz et al., in their study of women with previous CS and PP,(22) demonstrated increased risk of blood transfusion, coagulopathy and prolonged length of hospital stay, but unlike our study they didn't demonstrate higher risk of hysterectomy or organ injury in those patients with PP and previous CS. In addition, they showed higher risk of coagulopathy and one maternal death which were not found in our study. That study, was carried out only on multiparous women and had relatively smaller sample. Both studies did not show any significant difference in the perinatal outcomes between the two groups, both groups of women did not differ significantly in gestational age at delivery. The means of Apgar score and birth weight were similar in both groups, also the rate of admission to NICU.

However, one has to be cautious in the interpretation of the study findings because of possible confounding effects due to age and parity that were significantly different between the two groups. We were unable to conduct multivariate and regression analysis because of the small number of some peripartum complications in the two groups. Future studies with larger sample size are necessary to confirm the study findings. 


\section{Conclusion}

The study demonstrated a significant increase in the incidence of maternal morbidities such as hysterectomy, blood transfusion and organ injury in those patients with non-adherent PP with previous $\mathrm{CS}$, on the other hand there is no difference in perinatal outcome in the same group of patients. So proper counseling of those patients for possible complications and planning of delivery in properly equipped centers ready to handle these urgent situations is recommended.

\section{Abbreviations}

CS: Cesarean section

LSCS: lower segment cesarean section

MAPP: Morbidly adherent placenta previa

PP: Placenta previa

\section{Declarations}

- Ethics approval and consent to participate

The study method and protocol were approved by the Institutional Review Board (IRB) of the University Hospital/ Jordan University of Science and Technology

\section{- Consent for publication}

Not applicable

\section{- Availability of data and material}

The datasets used and/or analyzed during the current study are available from the corresponding author on reasonable request.

\section{- Competing interests}

The authors declare that they have no competing interests.

- Funding

No funds

\section{- Authors' contributions}

1. Amer Sindiani: Design, concept, data collection and analysis, and manuscript writing 
2. Nail Obeidat: Data Analysis and manuscript writing

3. Omar Abu-Azzam: Data collection and analysis

4. Heba Hijazi: Manuscript writing and analysis

\section{All authors read and approved the final manuscript}

\section{- Acknowledgements}

The authors would like to thank the study participants and Jordan University of Science and Technology

\section{References}

1. Ananth CV, Demissie K, Smulian JC, Vintzileos AM. Placenta previa in singleton and twin births in the United States, 1989 through 1998: a comparison of risk factor profiles and associated conditions. Am J Obstet Gynecol. 2003;188(1):275-81.

2. Sheiner E, Shoham-Vardi I, Hallak M, Hershkowitz R, Katz M, Mazor M. Placenta previa: obstetric risk factors and pregnancy outcome. The Journal of maternal-fetal medicine. 2001;10(6):414-9.

3. Parazzini F, Dindelli M, Luchini L, La Rosa M, Potenza MT, Frigerio L, et al. Risk factors for placenta praevia. Placenta. 1994;15(3):321-6.

4. Frederiksen MC, Glassenberg R, Stika CS. Placenta previa: a 22-year analysis. Am J Obstet Gynecol. 1999;180(6 Pt 1):1432-7.

5. Hershkowitz R, Fraser D, Mazor M, Leiberman JR. One or multiple previous cesarean sections are associated with similar increased frequency of placenta previa. Eur J Obstet Gynecol Reprod Biol. 1995;62(2):185-8.

6. Hendricks MS, Chow YH, Bhagavath B, Singh K. Previous cesarean section and abortion as risk factors for developing placenta previa. J Obstet Gynaecol Res. 1999;25(2):137-42.

7. Beckett MG, Allton CR, Davies CT, Davis I, Flynn JM, Grant EJ, et al. Building a scientific data grid with DiGS. Philos Trans A Math Phys Eng Sci. 2009;367(1897):2471-81.

8. Naftalin J, Paterson-Brown S. A pilot study exploring the impact of maternal age and raised body mass index on caesarean section rates. J Obstet Gynaecol. 2008;28(4):394-7.

9. Thomas J, Callwood A, Paranjothy S. The National Sentinel Caesarean Section Audit Report2001. 20 p.

10. Tan WC, Devendra K, Tan AS. Changing trends in indications for caesarean sections in a tertiary hospital. Ann Acad Med Singapore. 2003;32(3):299-304.

11. MacDorman MF, Menacker F, Declercq E. Cesarean birth in the United States: epidemiology, trends, and outcomes. Clin Perinatol. 2008;35(2):293-307, v.

12. Levine EM, Ghai V, Barton JJ, Strom CM. Mode of delivery and risk of respiratory diseases in newborns. Obstet Gynecol. 2001;97(3):439-42. 
13. Ananth CV, Smulian JC, Vintzileos AM. The association of placenta previa with history of cesarean delivery and abortion: a metaanalysis. Am J Obstet Gynecol. 1997;177(5):1071-8.

14. Silver RM, Landon MB, Rouse DJ, Leveno KJ, Spong CY, Thom EA, et al. Maternal morbidity associated with multiple repeat cesarean deliveries. Obstet Gynecol. 2006;107(6):1226-32.

15. Esakoff TF, Sparks TN, Kaimal AJ, Kim LH, Feldstein VA, Goldstein RB, et al. Diagnosis and morbidity of placenta accreta. Ultrasound Obstet Gynecol. 2011;37(3):324-7.

16. Alchalabi H, Lataifeh I, Obeidat B, Zayed F, Khader YS, Obeidat N. Morbidly adherent placenta previa in current practice: prediction and maternal morbidity in a series of 23 women who underwent hysterectomy. J Matern Fetal Neonatal Med. 2014;27(17):1734-7.

17. Appropriate technology for birth. Lancet. 1985;2(8452):436-7.

18. Lumbiganon P, Laopaiboon M, Gulmezoglu AM, Souza JP, Taneepanichskul S, Ruyan P, et al. Method of delivery and pregnancy outcomes in Asia: the WHO global survey on maternal and perinatal health 2007-08. Lancet. 2010;375(9713):490-9.

19. Mehrabadi A, Hutcheon JA, Liu S, Bartholomew S, Kramer MS, Liston RM, et al. Contribution of placenta accreta to the incidence of postpartum hemorrhage and severe postpartum hemorrhage. Obstet Gynecol. 2015;125(4):814-21.

20. Timor-Tritsch IE, Monteagudo A. Unforeseen consequences of the increasing rate of cesarean deliveries: early placenta accreta and cesarean scar pregnancy. A review. Am J Obstet Gynecol. 2012;207(1):14-29.

21. Rouse DJ, MacPherson C, Landon M, Varner MW, Leveno KJ, Moawad AH, et al. Blood transfusion and cesarean delivery. Obstet Gynecol. 2006;108(4):891-7.

22. Ayaz A, Farooq MU. Risk of adverse maternal and peri-natal outcome in subjects with placenta previa with previous cesarean section. Kurume Med J. 2012;59(1-2):1-4.

\section{Tables}

Table 1. The demographic and obstetric characteristics of women with no previous CS and those with previous CS. 


\begin{tabular}{|c|c|c|c|c|c|}
\hline \multirow[b]{2}{*}{ Maternal characteristics } & \multicolumn{2}{|c|}{$\begin{array}{l}\text { No } C / S \\
(N=54)\end{array}$} & \multicolumn{2}{|c|}{$\begin{array}{l}\text { Previous C/S } \\
(\mathrm{N}=36)\end{array}$} & \multirow[t]{2}{*}{$\mathrm{p}$-value } \\
\hline & $\mathrm{n}$ & $\%$ & $\mathrm{n}$ & $\%$ & \\
\hline Age, mean (SD) & \multicolumn{2}{|c|}{$31.0(4.8)$} & \multicolumn{2}{|c|}{$33.1(4.9)$} & 0.042 \\
\hline Parity, mean (SD) & \multicolumn{2}{|c|}{$2.0(1.7)$} & \multicolumn{2}{|c|}{$3.1(1.6)$} & 0.003 \\
\hline Previous miscarriage & 12 & $22.2 \%$ & 16 & $44.4 \%$ & 0.025 \\
\hline Previous evacuation & 8 & $14.8 \%$ & 13 & $36.1 \%$ & 0.026 \\
\hline Bleeding during pregnancy & 28 & $51.9 \%$ & 13 & $36.1 \%$ & 0.142 \\
\hline Indication for delivery & & & & & 0.078 \\
\hline Timed & 27 & $50.0 \%$ & 27 & $75.0 \%$ & \\
\hline Labour & 11 & $20.4 \%$ & 2 & $5.6 \%$ & \\
\hline Bleeding & 15 & $27.8 \%$ & 7 & $19.4 \%$ & \\
\hline Others & 1 & $1.9 \%$ & 0 & $0.0 \%$ & \\
\hline Placental location & & & & & 0.003 \\
\hline Anterior + central & 20 & $37.0 \%$ & 25 & $69.4 \%$ & \\
\hline Posterior & 34 & $63.0 \%$ & 11 & $30.6 \%$ & \\
\hline Gestational age at delivery, mean(SD) & 36.6 & (1.8) & 36.6 & (1.8) & 0.953 \\
\hline
\end{tabular}

CS: cesarean section, $p$ value of $<0.05$ is significant

Table 2. Peripartum complications among women with no previous CS and those with previous CS. 


\begin{tabular}{|c|c|c|c|c|c|}
\hline \multirow[b]{2}{*}{ Peripartum complications } & \multicolumn{2}{|c|}{$\begin{array}{l}\text { No C/S } \\
(N=54)\end{array}$} & \multicolumn{2}{|c|}{$\begin{array}{l}\text { Previous C/S } \\
(\mathrm{N}=36)\end{array}$} & \multirow[t]{2}{*}{$\begin{array}{l}\mathrm{p}- \\
\text { value }\end{array}$} \\
\hline & $\mathrm{n}$ & $\%$ & $\mathrm{n}$ & $\%$ & \\
\hline Organ Injury & 0 & $0.0 \%$ & 2 & $5.6 \%$ & $<0.005$ \\
\hline \multicolumn{6}{|l|}{ Blood transfusion } \\
\hline PRBC & 27 & $50.0 \%$ & 23 & $63.9 \%$ & 0.194 \\
\hline FFP & 2 & $3.7 \%$ & 6 & $16.7 \%$ & 0.034 \\
\hline$\geq$ 4units PRBC & 2 & $3.7 \%$ & 6 & $16.7 \%$ & 0.034 \\
\hline Hysterectomy & 0 & $0.0 \%$ & 4 & $11.1 \%$ & $<0.005$ \\
\hline $\begin{array}{l}\text { Other procedure( B Lynch, Uterine artery ligation, Bakri } \\
\text { balloon) }\end{array}$ & 2 & $3.7 \%$ & 3 & $8.3 \%$ & $<0.005$ \\
\hline ICU admission & 1 & $1.9 \%$ & 2 & $5.6 \%$ & 0.446 \\
\hline Postoperative hospital stay & & & & & 0.079 \\
\hline$\leq 4$ & 47 & $87.0 \%$ & 16 & $72.2 \%$ & \\
\hline$>4$ days & 7 & $13 \%$ & 10 & $27.8 \%$ & \\
\hline
\end{tabular}

CS: cesarean section, PRBC: packed red blood cells, FFP: fresh frozen plasma, ICU: intensive care unit, $p$ value of $<0.05$ is significant.

Table 3: Perinatal complications among women with no previous CS and those with previous CS 


\begin{tabular}{|llllll|}
\hline Fetal outcomes & No C/S & \multicolumn{3}{l|}{ Previous C/S } & p-value \\
& $(\mathrm{N}=54)$ & \multicolumn{2}{l|}{$(\mathrm{N}=36)$} & \\
& $\mathrm{n}$ & $\%$ & $\mathrm{n}$ & $\%$ & \\
\hline Age at delivery in weeks & & & & & 0.197 \\
\hline$<34$ & 3 & $5.9 \%$ & 1 & $3.3 \%$ & \\
\hline $34-36$ & 15 & $29.4 \%$ & 4 & $13.3 \%$ & \\
\hline$\geq 37$ & 33 & $64.7 \%$ & 25 & $83.3 \%$ & \\
\hline Apgar score at 5min, mean (SD) & $8.9(1.0)$ & & $8.8(1.1)$ & 0.495 \\
\hline Weight below 10th centile & 4 & $7.4 \%$ & 4 & $11.1 \%$ & 0.545 \\
\hline Birth weight, mean (SD) & $2932.1(475.0)$ & $2856.1(529.4)$ & 0.482 \\
\hline Admission to NICU & 9 & $16.7 \%$ & 9 & $25.0 \%$ & 0.333 \\
\hline Surfactant & 4 & $7.4 \%$ & 2 & $5.6 \%$ & 0.730 \\
\hline
\end{tabular}

CS: cesarean section, NICU: neonatal intensive care unit, $p$ value of $<0.05$ is significant. 